\title{
LA CONSUNCIÓN COMO REGLA DE PREFERENCIA EN EL MARCO DEL CONCURSO APARENTE DE LEYES*
}

[Consumption As a Rule of Preference in the Framword of the Simultaneous Application of Criminal Norms]

\author{
Osvaldo ARTaza V.** \\ RicARDO MENDOZA T.*** \\ LUCIANO ROJAS M.*
}

\begin{abstract}
RESUMEN
En el presente trabajo se desarrolla el criterio de la consunción del concurso aparente, delimitando su contenido a través de su consideración como regla de preferencia, la que operaría frente a supuestos en que el no desplazamiento de una de las normas de sanción de los tipos penales concurrentes infringiría el principio del non bis in idem. Para tales efectos, se distingue entre aplicabilidad interna y externa de normas penales, con el propósito de defender la tesis de que los supuestos de concurso aparente deben resolverse en sede de aplicabilidad externa de los tipos penales concurrentes y dando cuenta de cuáles serían los casos en que debiera operar la regla de la consunción para el desplazamiento de una de las normas de sanción de los tipos penales internamente aplicables al caso.
\end{abstract}

\section{Abstract}

The article develops the consumption criteria of the apparent concurrency of criminal laws, delimiting their content considering it as a rule of preference. This rule of preference operates in cases when the eventual production of legal effects of all the concurrent criminal laws infringes the non bis in idem principle. The article sustains the thesis that apparent concurrency of criminal law cases should be resolved using the external applicability of legal norms. To do that, the article distinguishes between external applicability of legal norms and internal applicability of legal norms. The thesis is developed showing in which cases we should use the rule of consumption to determine which of the criminal laws internally applicable to the case, is the one that will produce legal effects.

* El presente artículo se enmarca en el proyecto de investigación FONDECYT Regular No 1170276, titulado "Concurso de delitos como concurrencia de leyes penales”, cuyo investigador responsable es Francisco Maldonado F.

** Doctor en derecho y ciencias políticas, Universidad de Barcelona. Profesor de la Facultad de Ciencias Jurídicas y Sociales, Universidad de Talca. Dirección postal:

*** Egresado de Derecho de la Universidad de Talca. Ayudante de la Facultad de Derecho y Ciencias Sociales de la Universidad de Talca. Dirección postal: Quebec

**** Licenciado de Derecho de la Universidad de Talca. Investigador, Centro de Estudios de Derecho Penal, Universidad de Talca. Dirección postal: Quebec 415, Providencia, Santiago. Correo electrónico: lucianorojas@utalca.cl. 


\section{Palabras clave}

Derecho penal - consunción - aplicabilidad interna - aplicabilidad externa - especialidad - non bis in idem.

\section{KeYwords}

Criminal Law - consumption internal applicability - external applicability - speciality - non bis in idem.

Recibido el 25 de febrero de 2019 y Aprobado el 13 de septiembre de 2019

\section{INTRODUCCIÓN}

De acuerdo a lo establecido por el art. 75 del Código penal chileno ${ }^{1}$, un hecho puede constituir dos o más delitos ${ }^{2}$-lo que se conoce como concurso ideal $^{3}$. En tales supuestos el tribunal debe aplicar una regla

\footnotetext{
${ }^{1}$ Como es bien sabido, tal disposición se enmarca dentro de la regulación del "concurso". Para Matus, Jean Pierre, El concurso aparente de leyes penales (Santiago, Ediciones Jurídicas de Santiago, 2008), p. 27, el problema concursal se presenta cuando, en un mismo proceso, se puede imputar a una persona la realización del supuesto de hecho de varias normas penales. Ver también, Mañalich, Juan Pablo, El concurso de delitos. Bases para su reconstrucción en el derecho penal de Puerto Rico, en Revista Jurídica de la Universidad de Puerto Rico 74 (2005), p. 1027.tica solo puede a crl establecerl pecçificamente upuestos de unidad de hecho. Para tales efectos resulta fundamental establecer

${ }^{2}$ Es importante clarificar que este artículo solo se remitirá a ciertos problemas concursales que derivan de supuestos de unidad de acción, y específicamente, de unidad de hecho. Se debe recordar que uno de los criterios que se han utilizado para distinguir categorías concursales es la verificación de si el caso responde a supuestos de unidad o de pluralidad de acción, así, por ejemplo, Mañalich, El concurso..., cit. (n. 1), pp. 1027-1028, de acuerdo con el cual "la diferenciación entre el concurso ideal y el concurso real es la diferenciación entre el concurso en casos de unidad de acción y el concurso en casos de pluralidad de acción". Para tal autor, el concepto de unidad de acción "corresponde con los criterios que determinan la posibilidad de entender uno o diversos actos parciales como una sola acción" mientras que hablamos de unidad de hecho en los supuestos que, existiendo unidad de acción, esta es subsumible en distintos tipos penales, esto es "el concepto de unidad de hecho tiene como objeto la reconducción de varias infracciones de la misma o de distintas normas penales a una misma acción". Por lo mismo, la presencia del segundo supone la unidad de acción. Ver pp. 1027-1031 y MaÑALICH, Juan Pablo, El concurso aparente como herramienta de cuantificación penológica de hechos punibles, en CÁRDENAS, Claudia - FERDMAN, Jorge (coords.), El Derecho Penal como teoría y como práctica. Libro en homenaje a Alfredo Etcheberry Orthusteguy (Santiago, Legal Publishing Chile, 2016), p. 520, BASCUR, Gonzalo, Consideraciones acerca de los criterios de unidad de acción en la reciente jurisprudencia penal de la Corte Suprema (2011-2012), en Revista de Derecho Universidad Católica del Norte 23 (2016), 1, pp. 235-259.

${ }^{3}$ Caracterizado, según MaÑAlich, El concurso..., cit. (n. 1), p. 1035, por tratarse de un supuesto en que la "pluralidad de realizaciones delictivas ocurre en situaciones de unidad de acción. Esto significa que lo que subyace a la afirmación de un concurso
} 
penológica que impide aplicar la pena asignada a cada uno de los tipos penales concurrentes - como para el caso regulado por el art. 74, o concurso real- y obliga al tribunal a imponer la pena mayor asignada al delito más grave ${ }^{4}$. Con todo, y como se desprende del análisis de la doctrina mayoritaria, en ocasiones pese a que "formalmente" el hecho parecería caer bajo el campo de aplicación de dos o más tipos penales, tal situación sería solo aparente, ya que un ejercicio interpretativo correcto de la parte especial -como veremos más adelante: que tome en cuenta tanto el sentido como el campo de aplicación de cada uno de éstos- permitiría negar la situación de concurso en la que se hallarían tales tipos penales, en la medida que una decisión interpretativa correcta sería aquella que evitara contradicciones sistemáticas y que evidenciara que solo un tipo penal es el que regula el caso en concreto 5 . Como se podrá apreciar en este artículo, tal doctrina propone una serie de criterios -donde destaca la especialidad y la consunción ${ }^{6}$ - como herramientas interpretativas para así, especialmente a través del método sistemático, definir campos

ideal es una valoración negativa de una misma acción desde más de un punto de vista".

${ }^{4}$ En relación al fundamento de tal regulación ver Couso, Jaime, Comentario previo a los art. 74 y 75, en Couso, Jaime - Hernández, Héctor (dirs.), Código Penal Comentado. Parte General. Doctrina y Jurisprudencia (Santiago, Abeledo Perrot - LegalPublishing Chile, 2011), pp. 625-665.

${ }^{5}$ En este sentido Etcheberry, Alfredo, Derecho Penal. Parte General (3a edición, Santiago, Editorial Jurídica de Chile, 1999), II, p. 122; Garrido, Mario, Derecho Penal. Parte General (4a edición, Santiago, Editorial Jurídica de Chile, 2007), II, p. 456; Novon, Eduardo, Curso de Derecho Penal Chileno. Parte General (3a edición, Santiago Editorial Jurídica de Chile, 2005), II, p. 249; Cury, Enrique, Derecho Penal. Parte General (8 edición, Santiago: Ediciones Universidad Católica de Chile, 2005), p. 668; Labatut, Gustavo, Derecho Penal. Parte General (9a edición, actualizada por Julio Zenteno, Santiago, Editorial Jurídica de Chile, 1995), I, p. 173-174.

${ }^{6} \mathrm{Si}$ bien nuestra doctrina suele hacerse referencia a los 4 criterios clásicos, en la actualidad priman únicamente estos dos, restándole eficacia practica a los criterios de subsidiariedad y alternatividad. En este sentido MaÑALICH, El concurso..., cit. (n. 2), pp. 520-538; Cury, cit. (n. 5), p. 668; Garrido, cit. (n. 5), p. 457; NovoA, cit. (n. 5), p. 253, no obstante considerarlas solo como pautas para resolver un problema interpretativo, no pudiendo establecerse como reglas formuladas a priori. A su vez LABATUT, cit. (n. 5), p. 175, si bien hace mención a los 4 criterios concluye que los principios de alternatividad y subsidiariedad carecen de autonomía. Por otro lado, Matus, Jean Pierre, Comentario a los Artículos 74 a 78, en Politoff, Sergio - OrTíz, Luis (dirs.), Matus, Jean Pierre (coord.), Texto y comentario del Código Penal chileno, Tomo I, Libro Primero - Parte General (Santiago, Editorial Jurídica de Chile, 2002), pp. 389-393; Matus, cit. (n. 1), p. 305-322, en relación con el Código Penal español de 1995; Politoff, Sergio - Matus, Jean Pierre - Ramírez, María Cecilia, Lecciones de Derecho Penal Chileno. Parte General (2a edición, Santiago, Editorial Jurídica de Chile, 2004), pp. 456-464, intenta rescatar los principios de alternatividad y 
de aplicación heterogéneos de los tipos penales "aparentemente" concurrentes. Por tanto, en definitiva, y utilizando un término propio de la teoría del Derecho, solo una norma - de comportamiento y su correlativa norma de sanción- resultaría aplicable al hecho. Esta es la razón por la cual tal sector de la doctrina sostiene que en estos casos no existiría un verdadero concurso, sino que más bien "un problema interpretativo" $"$.

En forma reciente y en contra de esta aproximación tradicional, se ha sostenido entre nosotros que tales supuestos deben ser entendidos como una verdadera situación de concurso y que, por tanto, un mero ejercicio interpretativo correcto de la parte especial no permitiría solucionar el problema que subyace a la constatación de que un mismo hecho resulte regulado por más de un tipo penal y que, por lo mismo, solo sería correcto hablar de concurso aparente en forma metafórica ${ }^{8}$. Tal sector de la doctrina no niega que al hecho le resulte aplicable más de un tipo penal, sino que aduce la aplicación de una regla diversa -como veremos, una regla de segundo nivel ${ }^{9}$ y específicamente de aquellas conocidas como

subsidiariedad para su aplicación a casos que no quedan eventualmente resueltos por los criterios de especialidad y consunción.

${ }^{7}$ Así Cury, cit. (n. 5), p. 668; NovoA, cit. (n. 5), p. 247 haciendo referencia a esta "realización formal de dos o más tipos". Para más referencias, Couso, cit. (n. 4) p. 655 .

${ }^{8}$ Así, expresamente, Mañalich, cit (n. 2) p. 506. Acá, igualmente, se seguirá usando la denominación "aparente". Como señala el autor citado, tal denominación cumpliría la función de dar cuenta que solo un tipo penal es considerado como factor de determinación de pena. Ver, como exponentes de la postura que reconoce un verdadero concurso: Maldonado, Francisco, Delito continuado y concurso de delitos, en Revista de Derecho (Valdivia) 28 (2007), 2, pp. 207 y ss.; Matus, cit. (n. 1) p. 303304; Ossandón, Magdalena, El legislador y el principio del ne bis in idem, en Revista Política Criminal 13 (2018), 26, p. 969; PrAmBs, Claudio, ¿Es posible sancionar las lesiones y el homicidio en concurso ideal?, en Revista de Derecho de la Pontificia Universidad Católica de Valparaíso 34 (2010), p. 461 y ss.; BASCur, Gonzalo, Posesión ilegal de armas de fuego y publicación de la ley $n^{\circ} 20.813$. ¿Un problema de aplicación temporal de la ley penal más favorable?, en Revista de la Justicia Penal 7 (2017), p. 51. La posición contraria, en cambio, entiende que solo es correcto hablar de concurso en los casos en que se impone la pena de más de un delito o solo una de ellas en un régimen agravado, Cuerda Riezú, Antonio, Concurso de delitos y determinación de pena (Madrid, Editorial Tecnos, 1992), p. 17-23.

${ }^{9}$ Ver, especialmente, Maldonado, Francisco, Reiteración y concurso de delitos. Consideraciones sobre el artículo 351 del Código Procesal Penal a partir de la teoría general del concurso de delitos en el derecho chileno, en CÁRDENAS, Claudia - FERDMAN, Jorge (coords.), El Derecho Penal como teoría y como práctica. Libro en homenaje a Alfredo Etcheberry Orthusteguy (Santiago, LegalPublishing, 2016) p. 569. 
de "preferencia ${ }^{10 "}$ - para la solución de los casos en que en definitiva no pueda ser aplicada la regla penológica del artículo 75 del Código penal, sino que, más bien, se deba aplicar exclusivamente la norma de sanción del tipo penal preferente ${ }^{11}$. A diferencia de la posición anterior tal sector de la doctrina recurre a los criterios propios del concurso aparente mayormente, la especialidad y la consunción- no como argumentos interpretativos, sino como manifestaciones de la concreción de tal regla de preferencia que impide que el tribunal aplique en definitiva ambos tipos penales y, específicamente, sus consecuencias jurídicas -esto es, la sanción-.

El propósito de este artículo es propender a clarificar este problema a propósito del análisis del contenido y aplicación de la consunción como criterio autónomo del así llamado concurso aparente, entendiéndolo como una regla de preferencia de concreción del principio del non bis in idem, y no como un argumento interpretativo de la parte especial. Para tales efectos, se dará cuenta, en primer lugar, de la naturaleza de este concurso, con el propósito de explicar su consideración como un conjunto de reglas de preferencia que operan como concreción de la prohibición de doble valoración. Una vez se resuelva este problema se ahondará, en segundo lugar, en el contenido de esta regla de preferencia, abordando específicamente los problemas relativos a su campo de aplicación, esto es, la determinación del grupo de casos que regula y la relevancia de determinadas decisiones interpretativas - de la parte especial- para tales efectos -esto es, delimitar los grupos de casos que resultan regulados por la regla de preferencia "consunción"-.

\section{Desarrollo}

\section{Aplicabilidad interna y externa como criterios centrales para la} comprensión del concurso aparente

Con el objeto de dar cuenta del primer problema planteado, esto es, el de la naturaleza del denominado concurso "aparente" -esto es, si debe ser considerado un verdadero concurso o más bien un "problema interpretativo" - se debe ahondar en algunos conceptos fundamentales para su clarificación. Si se observa bien, para un sector -el que adhiere a la solución interpretativa- el concurso resulta aparente en la medida que el hecho, en definitiva, resulta regulado exclusivamente por un tipo penal, esto es, solo uno le resulta aplicable, mientras que, para otro sector de la doctrina, no se puede negar que más de un tipo regula el hecho,

\footnotetext{
${ }^{10}$ Así, Mañalich, cit. (n. 2), p. 507.

${ }^{11} \mathrm{Al}$ respecto, Maldonado, cit. (n. 9), p. 567-569.
} 
por tanto, que le resultan internamente aplicables más de un tipo. Con todo, esto no implica que al hecho le resulten externamente aplicables todos los tipos penales concurrentes, en la medida que opere otra regla que lo impida. Para comprender las diferencias entre una y otra postura conviene detenerse brevemente en el concepto de aplicabilidad y ciertas distinciones de suma relevancia ${ }^{12}$.

Es usual que se distinga en metodología jurídica, entre casos fáciles y casos difíciles, en atención a si la respuesta jurídica, esto es, la determinación de cómo reacciona el Derecho vigente frente al caso, resulta más o menos evidente o, por el contrario, a primera vista el mismo ordenamiento jurídico ofrece más de una solución posible ${ }^{13}$. Como se ha esgrimido -con razón- desde la teoría del Derecho, el concepto que resulta fundamental para la determinación de tal respuesta jurídica es el de aplicabilidad ${ }^{14}$, esto es, la detección de normas que, en primer lugar, regulen el caso y que, además, puedan ser aplicadas -en el sentido de producir efectos jurídicospor parte del tribunal. Para clarificar esta cuestión, abordaremos en forma breve algunos aspectos conceptuales fundamentales para el objeto de este artículo. Siguiendo a Navarro y Moreso, se debe tener en consideración que cuando se habla de aplicabilidad se puede estar haciendo referencia a dos aspectos diversos. En primer lugar, se puede señalar que la norma $N 1$ resulta aplicable si el tribunal tiene un deber institucional de usarla para que la misma produzca efectos jurídicos ${ }^{15}$. Tal deber institucional dependería, de acuerdo a esta postura, de la presencia de otra norma

\footnotetext{
${ }^{12} \mathrm{~A}$ pesar que este artículo, por motivos de extensión, se centra en la discusión nacional, puede consultarse las siguientes referencias en el derecho comparado que entienden el problema concursal como uno de aplicación de normas, denominadas de segundo nivel, que operan ante la concurrencia de normas (de primer nivel) que señalan penas a imponer ante la ocurrencia de supuestos de hecho, NinO, Carlos, El concurso en el derecho penal (Buenos Aires, Editorial Astrea de Rodolfo Depalma y Hnos. S.C.A, 1972), p. 47-68, Peñaranda, Enrique, Concurso de leyes, error y participación en el delito (Madrid, Editorial Civitas, 1991), pp. 50 y ss. Cid, José, Notas acerca de las definiciones dogmáticas de concurso de delitos, en Anuario de Derecho Penaly Ciencias Penales 47 (1994), Fasc. 1, pp. 29-30. Mir, Santiago, Derecho penal. Parte general (9a edición, Barcelona, Editorial Reppertor, 2011), pp. 662-668.

${ }^{13} \mathrm{Al}$ respecto, MarTínez, David, Metodología jurídica y argumentación (Madrid, Marcial Pons, 2010), pp. 31-34. Ver, en un sentido diverso de la discusión relativa a la existencia o no de casos fáciles, MARMOR, Andrei, Interpretación y teoría del derecho (Barcelona, Gedisa, 2001), pp. 165 y ss.

${ }^{14}$ Martínez, cit. (n. 13), p. 42, referida al problema de cuándo la norma "puede o debe ser usada por los jueces o las autoridades jurídicas en general para tomar y justificar decisiones".

${ }^{15}$ Navarro, Pablo - Moreso, José Juan, Aplicabilidad y eficacia de las normas jurídicas, en Isonomía 5 (1996), p. 125.
} 
en el sistema jurídico del que se trate, que permita u obligue a usar la norma $N 1$ para determinado caso ${ }^{16}$. En este sentido se dice que la norma resulta "externamente aplicable". Por otra parte, resulta posible hablar de aplicabilidad de la norma en referencia a su ámbito de validez, esto es, y dentro de otros aspectos, a la constatación de que efectivamente el caso está regulado o no por determinada norma. Para tales efectos se hablaría de aplicabilidad interna. En suma, la norma es internamente aplicable si dentro de su campo de aplicación puede ser subsumido el supuesto de hecho del que se trate -esto es, lo regule-, y es externamente aplicable si el mismo sistema jurídico permite u obliga a usarla para el caso del que se trate ${ }^{17}$.

En el ámbito del Derecho penal resulta especialmente ejemplificador de un caso difícil, aquellos supuestos en que, al momento de determinar la pena correspondiente a un hecho, se constate que más de un tipo penal lo regula, es decir, que más de un tipo penal resulten internamente aplicables. La dificultad asociada a tales casos radica en que frente a tal escenario puede operar tanto el llamado concurso ideal -si en definitiva el hecho constituye dos o más delitos- o un concurso "aparente" si, pese a la concurrencia de más de un tipo internamente aplicable, opera una regla que impide que alguno de estos pueda ser usado por el tribunal, es decir, surta efectos jurídicos. Esto es, el reconocimiento de un concurso ideal supone que al caso le resultan -interna y externamente- aplicables ambas normas. Por el contrario, el reconocimiento de que no se trata de un supuesto de concurso ideal, sino que "aparente", trae como consecuencia que no resulte posible al tribunal aplicar la regla penológica contenida en la disposición en comento, sino que, en definitiva, la pena se determinaría aplicando la norma de sanción de uno de los tipos penales -el externamente aplicable-.

Desde la perspectiva que interesa ahora, esto es, el de la constatación de que más de un tipo penal es aplicable al caso en particular, se debe señalar que un sector importante de nuestra doctrina sostiene que justamente aquello que diferenciaría el concurso ideal del llamado concurso "aparente", es que en el primer supuesto al hecho sería aplicable más de un tipo penal, mientras que en el segundo supuesto niegan tal escenario, sosteniendo que lo que lo caracteriza es que tal concurrencia de tipos penales internamente aplicables, sería solo aparente, ya que

\footnotetext{
${ }^{16}$ Martínez, cit. (n. 13), p. 42. Ver, al respecto, Moreso, José Juan - Vilajosana, Josep María, Introducción a la teoría del derecho (Madrid, Marcial Pons, 2004), p. 120.

${ }^{17}$ Navarro - Moreso, cit. (n. 15), p. 127. Para el ámbito del concurso aparente, expresamente Mañalich, cit. (n. 2), p. 507.
} 
una interpretación correcta de la parte especial, obligaría a llegar a la conclusión de que el hecho solo es regulado por un tipo penal, por lo que no se aplicaría la solución penológica del art. 75 , ya que operaría una regla implícita ${ }^{18}$-derivada a partir del argumento a contrario del mismo art. 75de acuerdo con la cual, cuando el hecho solo constituya un delito, solo puede aplicarse la pena asignada a este. Así, por ejemplo, Cury, en forma expresa niega la concurrencia de tipos penales internamente aplicables al sostener que existe concurso aparente cuando "un hecho parece satisfacer las exigencias de dos o más tipos diversos, pero, en definitiva, sólo será regulado por uno de ellos, en tanto que los demás resultarán desplazados por causas lógicas o valorativas" ${ }^{\prime 19}$. Como se puede apreciar, esta posición entiende que el concurso "aparente" se resuelve en sede de aplicabilidad interna, detectando el único tipo penal que, en definitiva, regula el caso.

Para la resolución del problema de la identificación de las normas que regulan el caso -lo que se conoce como interpretación en concretose debe haber tomado previamente ciertas decisiones interpretativas -de asignación de significado ${ }^{20}$ o interpretación en abstracto- de los tipos penales respectivos ${ }^{21}$. Esto es, la constatación de que determinada conducta cae dentro del campo de aplicación de una norma -esto es, el proceso de subsunción-, supone haber definido previamente el contenido

${ }^{18}$ Respecto al concepto de regla implícita y técnicas para su construcción, GuAstini, Riccardo, Interpretación y construcción jurídica, en Isonomía 43 (2015), p. 37.

${ }^{19}$ Cury, cit. (n. 5), p. 667. En el sentido de que el hecho solo se encuentra regulado por un tipo penal, EtCHeberry, cit. (n. 5) p. 122; NovoA, cit. (n. 5), p. 247; GarRIDO, cit. (n. 5), p. 456. En el derecho comparado, entre otros: SAINZ, Ángel, El concurso de delitos. Aspectos de política legislativa (Valladolid, Universidad de Valladolid, 1986), pp. 119-127 y p. 194, Gimbernat, Enrique, Concurso de leyes, error y participación en el delito (A propósito del libro del mismo título del profesor Enrique Peñaranda), en Anuario de Derecho Penal y Ciencias Penales 45 (1992), 3, pp. 833-854.

${ }^{20}$ En palabras de Chiassoni, Pierluigi, Técnicas de interpretación jurídica. Breviario para juristas (trad. de Pau Luque y Maribel Narváez, Madrid, Marcial Pons, 2011), p. 57. Fundamental, al respecto, ITURRALDe, Victoria, Interpretación literal y significado convencional. Una reflexión sobre los limites de la interpretación jurídica (Madrid, Marcial Pons, 2014), p. 27. Ver también, MARMOR, cit. (n. 13) pp. 27 y ss.; Raz, Joseph, Entre la autoridad y la interpretación. Sobre la teoría del derecho y la razón práctica (trad. de Hernán Bouvier y Pablo Navarro, Madrid, Marcial Pons, 2013), pp. 276 y ss.; SCHAUER, Frederick, Las reglas en juego. Un examen filosófico de la toma de decisiones basada en reglas en el derecho y en la vida cotidiana (trad. de Claudina Orunesu y Jorge Rodríguez, Madrid, Marcial Pons, 2004), pp. 283 y ss.

${ }^{21}$ Guastini, cit. (n. 18), p. 15. Ver, a propósito de la interpretación de los tipos penales, Ossandón, cit. (n.8), p. 967; MaÑalich, cit. (n. 2), pp. 517-518. 
de sentido del enunciado del que se trate, o en forma más específica: haber identificado la norma en vigor ${ }^{22}$. De esta forma se entiende el papel que jugarían -para la doctrina mayoritaria en comento- los criterios tradicionales -que reciben mayor aplicación en la actualidad- que se han propuesto para el reconocimiento de que, para la resolución del caso, se debe aplicar el concurso "aparente": esto es, el de la especialidad y el de la consunción.

Así las cosas, nuestra doctrina mayoritaria diría que cuando frente a determinada conducta se constata que "formalmente" - esto es, a través de un proceso incompleto de interpretación en concreto- se pueda subsumir tanto, por ejemplo, en el delito de estafa -del art. 468 del Código penalcomo en el de falsificación de instrumento privado -del art. 197 del Código penal-, si se recurre a un proceso adecuado de interpretación "en abstracto", esto es, de determinación del sentido de cada uno de los tipos penales concurrentes, donde se tome en consideración especialmente el "argumento sistemático ${ }^{23}$ ", se llegaría a la conclusión de que el caso solo estaría regulado por un tipo penal. Si se observa bien, el criterio de la especialidad no sería nada más que un criterio propio del argumento sistemático, por tanto, una técnica interpretativa para dotar de sentido a una norma. Como se desprende de esta aproximación metodológica, el desafío de la dogmática de la parte especial consistiría en detectar aquellos tipos penales que, en definitiva, no serían más que - desde el punto de vista del contenido de sentido- la especificación de otro ${ }^{24}$. Frente a la constatación -prima facie- de que la conducta puede ser subsumida en ambos tipos penales, la asignación de contenido de sentido a uno de estos, como una forma especial de estafa, al menos para la doctrina mayoritaria, implicaría sostener que el caso, en definitiva, solo está regulado por tal tipo penal, reduciendo así el campo de aplicación del otro tipo penal. Asimismo, frente a una unidad de hecho que pueda ser subsumida tanto en el tipo penal violación como en el de un abuso sexual, tal sector de

${ }^{22}$ Ver, GuAStini, cit. (n.18), pp. 14-15.

${ }^{23}$ Lo que está detrás de esta posición es la constatación de dos interpretaciones posibles de al menos uno de los enunciados: I1, que trae como consecuencia que el caso $\mathrm{C}$, se incluya dentro de su campo de aplicación, e I2 que, por el contrario, excluye de su campo de aplicación al caso C. De acuerdo con GuASTINI, Riccardo, cit. (n.18), p. 28, tal argumento o técnica consiste en decidir que una de las interpretaciones en disputa concordaría mejor con el "sistema del derecho", preservando así "la consistencia lógica y la coherencia (armonía) axiológica del derecho”. Ver también, MacCormick, Neil, Retórica y Estado de Derecho. Una teoría del razonamiento jurídico (trad. de José Ángel Gascón, Lima, Palestra editores, 2016) p. 225, especialmente en lo referente al argumento de la "armonización contextual".

${ }^{24}$ Couso, cit. (n. 4), p. 656. 
nuestra doctrina diría que tal aplicabilidad interna de ambos tipos penales sería solo aparente, en la medida que el caso, por aplicación del criterio de la consunción, solo caería bajo el campo de aplicación del delito de violación, ya que este último contendría el desvalor del primero ${ }^{25}$. Así, frente al hecho: $\mathrm{A}$ accede carnalmente a $\mathrm{B}$, aprovechándose de su incapacidad para oponerse, efectuando, al mismo tiempo, tocaciones de significación sexual y de relevancia, luego de una decisión interpretativa -en abstracto y en concreto- se llegaría a la conclusión que el hecho solo puede ser subsumido en el campo de aplicación del tipo "violación" y no en el de "abuso sexual".

La única forma de defender tal solución -tanto para el caso de la especialidad como el de la consunción- es sostener que a través de un proceso interpretativo se integra o adiciona, en uno de los tipos penales concurrentes, un elemento negativo que genera, como consecuencia, una relación de mutua exclusión entre los mismos ${ }^{26}$ : así, y solo a modo de ejemplo, el homicidio debiera ser entendido como matar a otro que no sea de aquellos sujetos contenidos en el tipo penal parricidio, y el abuso sexual como la ejecución de un acto de significación sexual y de relevancia

${ }^{25}$ Rodríguez, Luis, Delitos sexuales (2a edición, Santiago, Editorial Jurídica de Chile), p. 360-361; Matus, Jean Pierre - Ramírez, María Cecilia, Manual de Derecho Penal Chileno. Parte Especial (Valencia, Tirant lo Blanch, 2017). p. 248. Garrido, Mario, Derecho Penal. Parte Especial (4a edición, Santiago, Editorial Jurídica de Chile, 2010), III, p. 322.

${ }^{26}$ Se debe recordar que en el ámbito comparado se suele abordar la cuestión concursal distinguiendo una serie de problemas que derivarían de las relaciones en la que se encuentren los respectivos tipos penales. En este sentido KLUG, Ulrich, Sobre el concepto de concurso de leyes (trad. de Jorge Seña), en GARZÓN, Ernesto - ZimmERLING, Ruth (revs.), Problemas fundamentales de la filosofía y de la pragmática del derecho (Barcelona-Caracas, Alfa, 1989), pp. 62-63, en la doctrina nacional, MAÑALICH, cit. (n. 2), pp. 516-520. Estas relaciones son: heterogeneidad -o de mutua exclusión-, subordinación o interferencia. Que la relación entre los tipos aparentemente concurrentes sea de heterogeneidad, implicaría que estos se excluyan entre sí, es decir, ninguna unidad de comportamiento es subsumible en dos o más de los tipos en juego, por ello, al encontrarse estos en relación de heterogeneidad no pueden verse conjuntamente realizados por una única unidad de comportamiento. Dos tipos se encuentran en relación de subordinación si toda unidad de comportamiento de uno es subsumible bajo la descripción del otro, pero ello no ocurre a la inversa. Por último, dos tipos penales se encuentran en relación de interferencia si al menos una unidad de comportamiento es subsumible bajo uno de los tipos, pero no bajo el otro, ocurriendo lo mismo a la inversa, y al menos una unidad de comportamiento es a su vez subsumible en ambos tipos penales. Como resulta evidente, la solución interpretativa de la doctrina mayoritaria asume que lo que se conoce como concurso aparente serían supuestos de relaciones de exclusión entre tipos penales. 
-bajo las modalidades que transforman tal conducta en un ataque a la autodeterminación sexual- siempre y cuando no concurra, además, acceso carnal. Tal adición de elementos -negativos- resulta, sumamente inconveniente, ya que trae aparejada una serie de consecuencias adversas que ya han sido advertidas por nuestra doctrina ${ }^{27}$. Dentro de éstas, como señala Ossandón, destacan serios problemas que podrían presentarse como consecuencias asociadas al hecho de sostener que los tipos penales concurrentes se encontrarían realmente en relación de mutua exclusión, relativos al tratamiento de sujetos que actúan en $\operatorname{error}^{28}$, a la sanción en ciertos supuestos de coautoría o de participación ${ }^{29}$, y a la incompatibilidad de esta solución con lo que se conoce como "efectos residuales" del precepto desplazado ${ }^{30}$.

Con todo, y con independencia del ámbito de las consecuencias previamente descrito -que ya hacen aconsejable abandonar esta solución

${ }^{27}$ En sentido similar, OsSANdón, cit. (n. 8), p. 971-972. Para un análisis en detalle, Peñaranda, cit. (n. 12), pp. 40.

${ }^{28}$ Respecto del error, OsSANDÓn, cit. (n. 8), pp. 971-972 ha dado cuenta que, de entender el problema concursal como de interpretación entre tipos, la no concurrencia de otro sería un requisito negativo implícito, que precisamente por pertenecer al tipo debería estar cubierto por el dolo. Este razonamiento llevaría a la impunidad del supuesto de hecho en que un sujeto mata a un extraño bajo la errónea creencia de ser este, por ejemplo, su padre, por faltar un requisito objetivo del parricidio (la relación con el sujeto pasivo), y uno subjetivo del homicidio (el dolo respecto de no ser la víctima alguno de los sujetos pasivos que llevarían a la aplicación del parricidio).

${ }^{29}$ Ver, Ossandón, cit. (n. 8), p. 971 . Se ha sostenido que una de las consecuencias adversas de la posición criticada es que podría resultar incompatible con el tratamiento que, por ejemplo, se le suele dar usualmente al cómplice (extraneus) de un parricidio, en donde la doctrina mayoritaria defiende que se le debe imponer exclusivamente la pena por la intervención en un homicidio simple. Se ha señalado que de seguirse la posición que aborda el concurso aparente como uno de interpretación de los tipos en cuestión, el tipo preterido -homicidio- no habría sido realizado por falta de un elemento negativo, en tanto se entiende que el sujeto colaboraría con un parricidio. Ver también, en sede de autoría y participación, PeŃARAnda, cit. (n. 12), pp. 153 y ss.tica solo puede a crl establecerl pecçificamente upuestos de unidad de hecho. Para tales efectos resulta fundamental establecer

${ }^{30}$ En cuanto a los "efectos residuales", resulta relevante la determinación de la naturaleza del concurso aparente, ya que más allá de las implicancias de estos "efectos residuales", solo bajo la premisa de entender que en el concurso aparente las normas en juego resultan internamente aplicables, es posible a su vez reconocer la posibilidad cierta de recurrir a los efectos residuales de la norma desplazada, por ejemplo, que la norma desplazada sea externamente aplicada en el supuesto de que la norma preferente deje de ser aplicable. En este último sentido OsSANDÓn, cit. (n. 8), pp. 972; Matus, cit. (n. 1), p. 323 y ss.; MaÑAlich, cit. (n. 2), pp. 515-516. 
interpretativa-, también se debe reparar en que tal posición no advierte adecuadamente que, en estricto rigor, la identificación de un concurso "aparente" no es un asunto que se resuelva exclusivamente en sede de aplicabilidad interna, por lo que aquello que permite sostener que uno de los tipos penales no surtirá efectos jurídicos -en principio- no es la verificación de que no regule el hecho, sino que es un asunto de aplicabilidad externa. Este es el punto de partida de cierto sector de la doctrina chilena -a nuestro juicio correcto y que pasaremos a analizar a continuación- que entiende que este supuesto es un verdadero concurso, reconociendo así que al caso le resultan aplicables internamente más de un tipo penal, sin perjuicio de la posibilidad que algunas de éstas más bien de su norma de sanción- no surta efectos jurídicos. Como se indicó con anterioridad, que un hecho pueda ser subsumido en el campo de aplicación de dos tipos penales no implica, necesariamente, que los mismos -más bien que sus consecuencias jurídicas- sean externamente aplicables, por lo tanto, que puedan tener efectos jurídicos. Se debe recordar que tal posibilidad depende de que el mismo sistema jurídico del que se trate permita u obligue a "usar" tales normas ${ }^{31}$. Para tales efectos, será fundamental la constatación de que frente a situaciones en que los tipos penales concurrentes se encuentren en determinada relación opere otra regla -de preferencia- que obligue a aplicar -externamenteexclusivamente una de las normas de sanción de uno de los tipos penales concurrentes, desplazando así al resto. A continuación, se dará cuenta de la forma como la especialidad y la consunción, como criterios propios del concurso aparente, se dejan entender justamente como manifestaciones de tales reglas de preferencias.

${ }^{31}$ Ver, al respecto, Mañalich, cit. (n. 2), p. 508. Como señala el autor, de lo que se trata es de detectar reglas de preferencia que son aquellas que "fijan condiciones de aplicabilidad (externa) de normas de sanción pertenecientes al mismo sistema jurídico de referencia", por lo que se trata de reglas de "segundo orden, o metareglas". Es evidente que cuando se habla de "preferencia”, se está dando cuenta de una relación de "prioridad en la aplicación" de las respectivas normas de sanción de los tipos penales concurrentes. Fundamental, Cid, José, Notas acerca de las definiciones dogmáticas de concurso de delitos, en Anuario de Derecho Penal y Ciencias Penales 47 (1994), 1, p. 30, considerándolas como normas de segundo nivel. Conviene clarificar, adeccionespe l. ideridera las normasemitirse ac hecho el tribunal deba determinar la pena en atenciccionesp 


\section{Los principios del concurso aparente como concreción de la prohibición de la doble valoración}

Lo que corresponde ahora es dar cuenta de la delimitación de las reglas de preferencia que componen lo que se conoce como concurso "aparente". Para tales efectos, conviene atender al fundamento de la preferencia, esto es, los motivos por los cuales uno de los tipos penales -más bien su norma de sanción- se vería desplazado por el preferente. Si se observa con atención la doctrina del concurso "aparente", se podrá constatar cierto acuerdo en que en tales casos la aplicación -externa- del tipo preferente sería suficiente para expresar el desvalor del hecho, por lo que la aplicación -externa- de ambos podría aparecer innecesaria y resultar un exceso ${ }^{32}$. Con todo, se debe ahondar en este aspecto para dar cuenta de las razones por las cuales la aplicación conjunta de tales tipos penales pueda no resultar permitida para el adjudicador. Como resulta evidente, el legislador chileno no ha dado pautas expresas, al menos en el artículo 75, para la solución del problema, por lo que ha sido la doctrina y la jurisprudencia quienes han dotado de contenido tales criterios o principios del concurso "aparente". También existe cierto acuerdo, al menos en la doctrina especializada, en que tal contenido debe ser dotado a partir de la concreción del principio ${ }^{33}$ del non bis in idem, específicamente en su variante de prohibición de doble valoración o sobrevaloración ${ }^{34}$. Lo

${ }^{32}$ Se debe tener presente que esto se deriva de la relación en que se encuentran los tipos concurrentes -más bien las normas de sanción- es decir, la de una "redundancia punitiva circunstancial”, siendo la aplicación conjunta de las normas de sanción en juego "relativamente" desproporcionada, generándose un exceso punitivo, en este sentido MaÑAlich, cit. (n. 2), pp. 513-515. En el derecho comparado, Cid ha desarrollado en profundidad este punto, sosteniendo que el problema concursal se podría resumir en la aplicación de dos principios: principio de vigencia, que implica considerar cada uno de los elementos de los tipos penales concurrentes como criterio de determinación de pena, y el ne bis in ídem, que prohíbe considerar más de una vez al mismo elemento como criterio de determinación de pena, CiD, cit (n.12), p. 53-60.

${ }^{33}$ Nos referimos a casos de concreción en el sentido de que al no existir soluciones expresas la doctrina y jurisprudencia deben, siguiendo la terminología de GUASTINI, cit. (n. 18), p. 20, "obtener del texto normas no expresadas". excepcepciones implnormas denciacison los procesos de construcciste argumento para elegir aquella... ca el hecho de que "erencia

${ }^{34}$ Tanto Mañalich, Juan Pablo, El principio ne bis in idem en el derecho penal chileno, en Revista de Estudios de la Justicia 15 (2011), p. 160, como Ossandón, cit. (n. 8), p. 973, entienden el concurso aparente como una manifestación del principio del non bis in idem como estándar de adjudicación sustantivo o prohibición material. En nuestra doctrina, suele vincularse tal principio con el criterio de la consunción, en este sentido Garrido, cit. (n. 5), p. 459; EtCheberry, cit. (n.5), p. 125; NovoA, 
anterior es de suma relevancia, en la medida que se entienda que tales criterios, con diferencias de suma relevancia, debieran interpretarse, a su vez, como una concreción de tal principio ${ }^{35}$.

Por lo mismo, resulta necesario referirse brevemente al contenido del principio del non bis in idem, el cual, según nuestra doctrina, comprende una doble prohibición o -en palabras de Mañalich- un doble estándar ${ }^{36}$. Así, por una parte, este principio comprende una prohibición material o estándar de adjudicación sustantivo, entendido en el sentido de que un mismo hecho $-\mathrm{o}$ aspecto del hecho o hechos- no puede ser doblemente valorado -o en forma reiterativa-para la imposición de una sanción. Y, por otro lado, este principio comprende un estándar o prohibición procesal, el cual impide someter a un individuo a dos o más procesos simultáneos o sucesivos que recaigan sobre los mismos hechos ${ }^{37}$. Resulta evidente que para el tema aquí analizado es pertinente remitirnos exclusivamente al ámbito de prohibición material derivada de este principio, prohibición que encuentra su mayor implicancia práctica en aquellas situaciones en que un mismo hecho satisface dos o mas descripciones delictivas y se debe determinar, justamente, si la aplicación -externa- de todas estas resulta permitida. Para resolver este problema se debe tener en cuenta, como lo ha

cit. (n. 5), p. 156. En tanto MATUs, cit. (n. 6), p. 389, lo vincula con los principios de alternatividad, subsidiariedad y especialidad, ya que la aplicación del principio de consunción encontraría su justificación en el principio de la insignificancia.

${ }^{35}$ Se ha discutido respecto a la naturaleza del non bis in idem, si este posee el carácter de principio o más bien de una regla. OsSANDón, cit. (n. 8), p. 978 entiende que el non bis in idem es una regla, ya que posee características propias de una regla que lo distinguen de los principios: "concretan cuales son los supuestos de hecho a los que se refieren, operan para casos concretos, no admiten aplicación gradual y operan por subsunción, no por ponderación”. De la misma opinión, HeRnÁNDEZ, Héctor, Actividad administrativa, procedimiento sancionatorio-administrativo y proceso penal: algunas necesidades de coordinación legal, en ARANCIBIA, Jaime - AlarCón, Pablo (coords.), Sanciones Administrativas. X jornadas de Derecho Administrativo, Asociación de Derecho Administrativo (Santiago, Thomson Reuters, 2014), p. 572. En cambio, Mañalich, cit. (n. 34), pp. 142-143, entiende que el principio del non bis in idem, en cuanto estándar sustantivo de adjudicación, no representa más que una concresión de la prohibición de exceso, derivada a su vez del principio general de proporcionalidad. Se debe tener presente que la consideración del non bis in idem como principio, no impide su aplicación en forma de regla -de preferencia en este caso- a través de su concreción, para el supuesto de que se trate.

${ }^{36}$ Mañalich, Juan Pablo, El principio..., cit. (n. 34), p.140, en el mismo sentido MaÑalich, Juan Pablo, El principio ne bis in idem frente a la superposición del derecho penal y el derecho administrativo sancionatorio, en Revista Politica Criminal 9 (2014), 18, p. 543.

${ }^{37}$ En este sentido OsSANdón, cit. (n. 8), p. 953; MaÑalich, cit. (n. 34), p. 140. 
señalado parte de nuestra doctrina, que el principio del non bis in idem se traduce en una concreción de la prohibición de exceso, derivada esta a su vez del principio de proporcionalidad. ${ }^{38}$ En este sentido, el principio del non bis in idem, en su variante de prohibición de doble valoración, resulta vinculante directamente para el adjudicador ${ }^{39}$, el que debe determinar, atendiendo al resultado de ciertas decisiones interpretativas de los tipos penales concurrentes, si existen antecedentes normativos que permitan concluir que la valoración "doble" del hecho o aspectos del hecho, signifique una mera reiteración -en este sentido, un exceso-, en razón de que concurra una relación de "redundancia punitiva circunstancial ${ }^{40}$ " entre los tipos penales concurrentes, la que permitiría desplazar a una de las normas de sanción de los mismos, ya que su aplicación conjunta vulneraría la prohibición de doble valoración.

Ahora bien, en cuanto a su consagración normativa, el principio del non bis in idem no se encuentra expresamente comprendido en nuestro ordenamiento jurídico, no obstante, de acuerdo con nuestra doctrina, su variante de prohibición de doble valoración se extrae de algunos preceptos de nuestro Código penal ${ }^{41}$. Así, por ejemplo, el artículo 63 del mismo, prohíbe al juzgador incrementar la pena asociada a un delito, en razón de circunstancias agravantes que sean inherentes al mismo, es decir, si esta circunstancia agravante ya se tuvo en consideración al establecer el delito o se encuentra contenida en el mismo, o en los supuestos en que sin la concurrencia de esta circunstancia no puede cometerse el delito del que se trate. Como se puede apreciar, tal disposición otorga importantes criterios para la delimitación de los casos en que determinadas circunstancias no pueden ser valoradas por el juzgador -en este caso para agravar la pena-, ya que en caso contrario se estaría vulnerando el principio del non bis

${ }^{38}$ MañAlich, cit. (n. 34), p. 142, en tanto OsSAndón, cit. (n. 8), pp. 978-979, si bien vincula el principio del non bis in idem a consideraciones de proporcionalidad, también lo hace a consideraciones de seguridad jurídica, lo cual permitiría conectarlo a su vez con el principio de legalidad.

${ }^{39}$ En este sentido Mañalich, cit. (n. 34) p. 143; en el mismo sentido OsSANdón, cit. (n. 8) p. 975, pero entendiendo que sostener que el principio del non bis in idem obliga únicamente al juzgador, y no al legislador, implica que el mismo tienda a su desaparición.

${ }^{40}$ MaÑAlich, cit. (n. 2), p. 513.

${ }^{41}$ En cuanto a su consagración supra legal, solo puede predicarse esta de forma indubitada respecto de su variante de prohibición procesal no así -al menos directamente- de su variante prohibición de doble valoración. En este sentido MAŃALICH, cit. (n. 34), pp. 141-142; OsSANdón, cit. (n. 8), p. 957, su consagración supra legal como estándar o prohibición procesal estaría dada por su inclusión en el Pacto Internacional de Derechos Civiles y Políticos en su artículo $14 \mathrm{~N}^{\circ} 7$ y en la Convención Americana sobre Derechos Humanos en su artículo $8 \mathrm{~N}^{\circ} 4$. 
in idem en su variante prohibición de doble valoración ${ }^{42}$. Asimismo, se ha considerado que también constituyen un ejemplo de la consagración normativa de esta prohibición aquellas cláusulas que establecen la solución de una subsidiariedad expresa ante un posible concurso de delitos, como la contenida en el artículo 391 del Código penal ${ }^{43}$, o la establecida en el artículo 488 en relación al delito de daños ${ }^{44}$.

La aplicación de los criterios propios del concurso "aparente" también puede ser comprendida como una manifestación de este principio y, específicamente, como reglas que significan una concreción del mismo. Así, por ejemplo, respecto a la especialidad como regla de preferencia su contenido sería el siguiente ${ }^{45}$ : frente a los casos en que un hecho sea regulado por dos o más normas pero una de estas sea una especificación de la o las otras, el tribunal solo podrá aplicar externamente ésta ${ }^{46}$. La consecuencia jurídica, emanada de la aplicación del principio del non bis in idem, concretado por la regla de la especialidad, es que no puede reconocerse un concurso ideal. Una vez clarificado el contenido de sentido de la regla, debemos determinar su campo de aplicación. Para tales efectos, resulta especialmente clarificador considerar que existe cierto acuerdo en que tal regla opera para aquellos casos en que los tipos penales concurrentes se encuentren en determinada relación lógica entre ellos, esto es, la de la subordinación, la que conlleva, necesariamente que uno de los tipos penales concurrentes sea comprendido como una “especificación semántica ${ }^{47 ”}$ del otro.

${ }^{42}$ En este sentido Mañalich, cit. (n. 34), p. 161; Ossandón, (cit. n. 8), pp. 983984; Etcheberry, cit. (n. 5), p. 125, Couso, Jaime, Comentario al artículo 63, en Couso, Jaime - Hernández, Héctor (dirs.), Código Penal Comentado. Parte General. Doctrina y Jurisprudencia (Santiago, Abeledo Perrot - LegalPublishing, 2011), pp. 572-578.

${ }^{43}$ Mañalich, cit. (n. 34) p. 161.

${ }^{44}$ ETCHeberRy, cit. (n. 5) p. 125.

${ }^{45} \mathrm{Si}$ bien es cierto el propósito de este artículo es el análisis de la consunción como regla de preferencia, resulta imprescindible, para tales efectos, su comparación con la regla de la especialidad, con el solo propósito de poder diferenciar adecuadamente su contenido y ámbito de aplicación.

${ }^{46}$ Respecto a la especialidad, como regla de preferencia, ver FerRer, Jordi RodrígueZ, Jorge Luis, Jerarquias normativas y dinámica de los sistemas jurídicos (Madrid, Marcial Pons, 2011), p. 138, de acuerdo con el cual "se prefiere la norma que regula un caso más específico sobre la que regula un caso más general en el que el primero está incluido".

${ }^{47}$ MaÑAlich, cit. (n. 2), p. 529, entendiendo la relación de subordinación como se señaló anteriormente en supra n.26. Es usual, en la doctrina, hablar de relaciones de especialidad, en este sentido Matus, cit. (n. 6), p. 389. s usual concurrentes se 
En este sentido, la aplicación de la regla de preferencia "especialidad", sí conlleva decisiones interpretativas $-y$ solo en este sentido puede ser entendido como un problema interpretativo-, ya que es la decisión de considerar que el contenido del sentido de un tipo penal es el de ser la especificación de otro tipo, lo que trae como consecuencia que opere determinada regla de preferencia -la de especialidad-. Por lo mismo, la doctrina chilena está en lo correcto cuando sostiene que la especialidad como principio del concurso "aparente" depende, principalmente, de criterios lógicos ${ }^{48}$. Ahora, detrás de tal decisión se está constatando entonces, al ser el principio del non bis in idem un principio dirigido a regular la labor del adjudicador, que la solución del caso -difícil- pasa por asumir que, de acuerdo al Derecho penal vigente, al hecho solo se le aplica la norma de sanción del tipo interpretado como una especificación semántica del otro, y que una decisión contraria conllevaría la vulneración de la prohibición de la doble valoración. La no aplicación de la regla de preferencia -esto es, que el caso no se encuentra regulado por la mismatambién depende de decisiones interpretativas, esto es, la consideración de que determinado tipo penal no puede ser comprendido exclusivamente como la especificación de otro, sino que como algo más que éste, lo que pasa, generalmente, por la constatación de que el objeto de protección de uno y otro no resultan coincidentes, por lo que, en tales supuestos, el desplazamiento de una de las normas de sanción resultaría una decisión errónea desde el punto de vista de la solución del caso de acuerdo al Derecho penal vigente, debiendo reconocerse un concurso ideal ${ }^{49}$.

encuenticirentes sea comprendido como uan especificacisamente los tipos penales concurrentes se encuent

${ }^{48}$ En este sentido Etcheberry, cit. (n.5), p. 123; Garrido, cit. (n. 5), p. 457; NovoA, cit. (n.5), pp. 253-254; CuRY, cit. (n. 5), p. 669, sin embargo, aclara que la pura apreciación lógica es insuficiente para alcanzar una solución, siendo necesario recurrir a elementos axiológicos. En tanto MAÑAlich, cit. (n. 2), p. 529, considera que el criterio de la especialidad "es intrínseco a la estructura lógico-semántica de la subordinación como relación en que se encuentran los tipos concurrentemente realizados", esto quiere decir que el tipo general ya se encuentra contenido en el tipo especial, por lo que la "subsidiariedad" de la ley general viene dada en la "esencia de los tipos". Sin embargo, tal dependencia a criterios lógicos no es absoluta, ya que entender la aplicación externa de más de un tipo penal como una infracción al ne bis in ídem implica también un criterio valorativo, en tanto, el concurso aparente supone la superposición de la significación delictiva de los tipos concurrentes, MAÑALICH, cit. (n. 2), p. 505.

${ }^{49}$ En estos casos resulta correcta la fórmula del "in dubio pro concurso ideal" señalada por MAÑALICH, cit. (n. 2), p. 538, en relación a que en virtud del "mandato de exhaustividad", la sentencia respectiva debe resultar "suficientemente expresiva del juicio de desaprobación jurídica referido a cada especifico contenido de significación delictiva ejemplificado por el comportamiento imputable del condenado". 
Como se podrá apreciar a continuación, la determinación de los supuestos regulados por la regla de preferencia conocida como "consunción" resultará especialmente compleja, ya que, si bien existe cierto acuerdo respecto al sentido o significado de tal regla, podremos apreciar cierta dificultad para delimitar los casos que deben entenderse regulados por ésta. Tal problema se debe, como bien señala nuestra doctrina, a que a diferencia de la regla de preferencia "especialidad", que respondería -especialmente- a criterios lógicos, la consunción, para la delimitación de su aplicación, atendería principalmente a decisiones de índole axiológicas o valorativas ${ }^{50}$. Lo primero que debemos considerar es que, en relación al sentido de esta regla, nuestra doctrina tradicional sostiene que la misma lleva a desplazar a uno de los tipos "aparentemente realizados", sancionando el hecho únicamente con la norma aplicable, en aquellos supuestos en que "el disvalor delictivo que implica la ejecución de uno de ellos contiene al que supone la realización del otro u otros" ${ }^{\text {51 }}$. Al igual que en el supuesto de la especialidad, la consecuencia de la aplicación de la consunción, para los supuestos de unidad de hecho, será la imposibilidad de reconocer el concurso ideal con las consecuencias penológicas que este implica. La principal diferencia que presenta con la especialidad, desde el punto de vista de su campo de aplicación, radica en que, mientras la primera se circunscribe a los supuestos en que los tipos penales concurrentes se encuentren en relación de subordinación, no existe consenso en relación a la segunda, esto es, no hay consenso relativo a la clase de relación entre tipos penales frente a la que opera ${ }^{52}$.

${ }^{50}$ En este sentido Cury, cit. (n. 6), 2005, p. 669; EtCheberry, Alfredo, El concurso aparente de leyes penales, (Santiago, Editorial Jurídica de Chile, Colección de seminarios e institutos, volumen II, 1957), p.51; GARRIDO, cit. (n. 5), p. 459; NovoA, cit. (n. 5), p. 256. Para MAŃAlich, cit. (n.2) p. 535, la aplicación del criterio de la consunción lleva asociado un "irreductible margen de incertidumbre", ya que recurrir a él implica realizar una "comparación cualitativa de la intensio de los dos o más tipos desde el punto de vista del concreto objeto de juzgamiento que satisface cada una de las descripciones en cuestión”. Al igual como se explicó para el caso de la especialidad, donde no se puede negar la relevancia de aspectos "valorativos", la referencia a criterios valorativos como los más relevantes para solucionar este grupo de problemas no implica que la consunción esté exenta de criterios lógicos, al contrario, la misma relación de interferencia supone un criterio lógico, PeÑaranda, cit. (n. 12), p. 51.

${ }^{51}$ Cury, cit. (n. 5) p. 669, en igual sentido MuÑoz, Humberto, Contribución al estudio de la teoría de los concursos de delitos, en Revista Chilena de Derecho 13 (1986), 2, p. 378, entendiendo el criterio de la consunción como problema relativo a la antijuridicidad, mientras que el criterio de la especialidad resultaría ser un problema de tipicidad.

${ }^{22}$ En Chile Mañalich, cit. (n. 2), p. 535, entiende que la consunción opera en aquellos casos en que la relación lógico- semántica en que se encuentran los 
Sin perjuicio de este aspecto, en este artículo nos remitiremos, por fines pedagógicos, exclusivamente a las condiciones para la aplicabilidad de tal regla de preferencia frente a supuestos en que los tipos concurrentes se encuentren en relación de interferencia. Tal decisión se justifica, además, en la medida que lo que interesa acá, como concreción de la prohibición de doble valoración, es la determinación de los casos en que el adjudicador no pueda valorar determinados elementos -como veremos, comunes entre los tipos concurrentes- para fundamentar la aplicación externa de éstos en forma conjunta. Lo anteriormente señalado merece ser clarificado a través de un análisis breve de la naturaleza de la relación de interferencia entre tipos penales, para así comprender su relevancia para el objeto de este artículo.

Una aproximación parcial a este aspecto podría hacer pensar que la relación de interferencia, al igual que la de subordinación, se detecta atendiendo a la relación en la que se encuentran determinados tipos penales en forma intrínseca entre sí. Esto es, se daría en los casos en que el tipo penal T1 presente tanto elementos comunes con el tipo T2, como elementos que no pertenezcan a este último, y viceversa ${ }^{53}$. Con todo, y como se podrá apreciar a continuación, la relación en comento solo puede ser detectada a través de la determinación de los tipos penales que regulan el hecho del que se trate, por tanto, se debe constatar a través de un ejercicio de interpretación en concreto y la definición de las normas internamente aplicables. Lo anterior es de suma relevancia, en la medida que se puedan detectar relaciones de interferencia entre tipos penales, que no la presentarían si no es en razón de los resultados

tipos concurrentemente realizados es la de interferencia. No obstante, esta no es la posición mayoritaria en nuestra doctrina, ya que la misma suele incluir en el criterio de la consunción los actos copenados como supuestos de aplicación de este, lo que escapa a una posible relación de interferencia entre los tipos. Esto implica a su vez reconocer que el criterio de la consunción permitiría excluir los efectos de un posible concurso real, en aquellos supuestos de pluralidad de hecho. En este último sentido Etcheberry, cit. (n. 5) pp. 124-127, Matus, cit. (n. 1), p. 320, NovoA, Eduardo, cit. (n. 5) pp. 257-258, este último haciéndose cargo expresamente de los planteamientos que limitan el campo de aplicación del criterio de la consunción a aquellos supuestos de unidad de hecho, estimando conveniente esto, solo en aquellos casos de exceso que generan los actos anteriores y posteriores copenados.

${ }^{53}$ Es clásico el ejemplo entregado por la doctrina para clarificar el criterio de la consunción, de la relación entre los tipos de daños de cosa ajena establecido en los artículos 484 y 487 del Código penal, violación de domicilio de artículo 144 del mismo Código, y el delito de robo con fuerza en las cosas del artículo $440 \mathrm{~N}^{\circ} 1$, efectivamente la relación entre estos tipos es de interferencia, ya que si bien presentan elementos comunes entre sí, cada uno presenta también elementos que no es posible encontrar en los demás . 
de la subsunción de un hecho en particular. Con un ejemplo se podrá entender a cabalidad lo recientemente señalado. El hecho: " $A$ apunta con un arma de fuego prohibida a B, amenazándolo con que, si no le entrega determinada pertenencia, le disparará" ${ }^{4}$. Una interpretación en concreto - debemos recordar que esta consiste en la definición de las normas que regulan el caso- traería como resultado que tal unidad de hecho puede ser subsumida tanto en el delito de robo con intimidación (art. 436 del Código penal) como en el tipo penal del porte ilegal de arma de fuego (art. 9 Ley 17.798). Tal relación de interferencia se puede constatar fácilmente si se piensa en el tipo penal de robo como el conjunto $A$ y el tipo penal porte de arma como el conjunto $B$. Solo al verificar que el hecho puede ser subsumido en $A$ y en $B$ se constata que tales tipos penales se encuentran en una relación de interferencia, ya que los tipos penales en abstracto no presentan realmente elementos en común ${ }^{55}$. Es el ejercicio de subsunción el que determina la presencia de un espacio en común entre los dos conjuntos, esto es: que la intimidación se haya efectuado con un arma de fuego. Con todo, el espacio común está limitado a ciertos elementos, y cada tipo penal presenta, además, elementos particulares: es decir, que solo pueden ser integrados en $A$ la apropiación de cosa mueble ajena y la coacción- así como en $B$-el tratarse de un arma prohibida-. En este sentido, la constatación de una relación de interferencia depende, necesariamente, de decisiones interpretativas en concreto u orientadas al hecho.

Sin embargo, constatar que los tipos penales concurrentes se encuentran en relación de interferencia es absolutamente insuficiente para concluir que debe ser aplicada la regla de preferencia "consunción", ya que tal relación puede dar pie, indistintamente, tanto a un supuesto de concurso ideal como "aparente". Por tanto, un análisis adecuado de la aplicación de tal regla no puede satisfacerse con la mera referencia a la detección de una relación de interferencia. Lo medular será, para tales efectos, atender al contenido de sentido de la consunción como regla, esto es: para los casos en que el hecho, pueda ser subsumido en más de un tipo penal, pero uno de estos represente completamente el desvalor del hecho, el tribunal deberá reconocer un concurso aparente, aplicando externamente exclusivamente tal tipo penal -el que "consume" al resto-. Cualquier decisión contraria, esto es, aquella que aplique externamente

${ }^{54}$ Se debe aclarar que tal supuesto es usado solo con el fin de ejemplificar la relación de interferencia. El legislador, a través del artículo 17 A de la Ley 17.798 modificada por la Ley 20.813, ha dispuesto expresamente que en aquellos casos deberá aplicarse la regla de concurso material prevista en el art. 74 del Código penal.

${ }^{55}$ En forma similar MaÑAlich, cit. (n. 2), p. 535. 
las normas de sanción de todos los tipos concurrentes, vulneraría el principio del non bis in idem. Por el contrario, si en definitiva ninguno de los tipos penales representa completamente -esto es, en forma globalel desvalor del hecho, el tribunal debe reconocer un concurso ideal. La decisión de si frente al hecho uno de los tipos penales comprende completamente su desvalor o no, depende necesariamente del resultado de un ejercicio interpretativo de tales tipos penales ${ }^{56} \mathrm{y}$ una comparación -en concreto- relativa a si el desvalor que representa el hecho se ve satisfecho por uno de estos, o existen aspectos de tal desvaloración no comprendidos en este y sí en otro de los tipos concurrentes. Así, por ejemplo, y volviendo al supuesto de hecho anterior, si se considera que éste solo resulta desvalorado en atención a la afectación de la libertad y propiedad del afectado, el tipo penal externamente aplicable resulta el de robo con intimidación desplazando así, no por razones interpretativas, sino por aplicación de la regla de preferencia -consunción- al de porte de arma de fuego. En estricto rigor, entonces, la consunción como regla de preferencia debe ser aplicada en aquellos casos en que, por decisiones interpretativas previas, se defina que un tipo penal representa completamente el desvalor del hecho. En cambio, si se entiende que el hecho también resulta desvalorado por la afectación de intereses diversos -por ejemplo, supraindividuales- resultantes del porte del arma de fuego prohibida, ya no puede reconocerse que el tipo de robo contenga completamente su desvalor $y$, por ende, el tipo de porte no puede verse desplazado ${ }^{57}$, esto es, el caso no cae bajo el campo de aplicación de la regla de preferencia -consunción-, debido a que existen fundamentos normativos que avalan que el elemento común -que da a pie a la relación de interferencia entre los tipos penales concurrentes- sea legítimamente desvalorado para fundamentar la aplicación de ambos - porte de arma y robo con intimidación- sin infringir la prohibición de doble valoración.

Uno los cometidos que ha cumplido hasta el momento nuestra doctrina es la de reconocer grupos de casos genéricos donde estaría relativamente consolidada la opinión de que operaría un concurso "aparente" por consunción ${ }^{58}$. Si se observa el desarrollo doctrinal de esta

${ }^{56}$ Novoa, cit. (n. 5), p. 251. Mañalich, cit. (n. 2), p. 535.

${ }^{57}$ Como mencionamos anteriormente, el ejemplo es meramente ilustrativo en tanto el legislador incluyó una regla concursal expresa mediante la Ley 20.813.

${ }^{58}$ Ver, especialmente, MATUs, cit. (n. 1), pp. 318-320, quien señala que se puede mencionar en este grupo de casos: los actos anteriores copenados, los actos propiamente acompañantes típicos o copenados y los actos posteriores copenados. Con subdivisiones en cada grupo de casos. Con todo, el autor precisa que esta lista no es en ningún caso taxativa o definitiva, ya que, en su concepto de consunción, esta no permite la postulación de una lista con esas características, debido a que el problema 
institución se puede constatar que la concreción indicada puede adoptar dos formas diversas. En un primer lugar, el desplazamiento de uno de los tipos penales concurrentes podría justificarse en atención a que el mismo solo puede ser comprendido como una forma de protección menos intensa del mismo interés que el que en definitiva resulte el único externamente aplicado. Para tales casos lo medular será la verificación de que la valoración del elemento común entre tipos concurrentes no sea, en definitiva, redundante desde la significación delictiva del hecho de que se trate ${ }^{59}$, para lo cual resultará fundamental la determinación de la significación delictiva en abstracto de los tipos concurrentes. En segundo lugar, el desplazamiento respectivo podría verificarse, de acuerdo a nuestra doctrina, en supuestos en que pese a detectar autonomía de los tipos concurrentes desde el punto de vista de su significación delictiva en abstracto, se presente una relación de inherencia tal entre ellos que justifique que uno de los tipos se vea consumido debido a que en definitiva resulta inevitable -o necesario- para la realización del tipo externamente aplicado y, por tanto, no se constate una significación delictiva autónoma en concreto.

a) Aplicación de la regla de preferencia por resultar un tipo una forma menos intensa de protección del mismo interés.- Con el objeto de analizar el primer supuesto detectado, propondremos el siguiente ejemplo. Frente al hecho: A realiza una serie de tocaciones en zonas genitales de B, menor de 13 años, mientras capta imágenes de tal conducta. En atención a lo recientemente señalado queda en evidencia que tal hecho puede ser subsumido tanto en el tipo penal "abuso sexual de menor de 14" -art. 366 bis del Código penal-, como en el de "producción de material pornográfico infantil" -art. 366 quinquies del Código penal-. Tales tipos penales, luego del proceso de subsunción referido, se encuentran en relación de interferencia, en la medida que no solo presentan un elemento en común -en este caso, las tocaciones en zona genital- sino que también algunos exclusivos de cada uno de los tipos concurrentes. De acuerdo a lo anteriormente señalado, la solución del caso dependerá de la determinación de si la valoración de tal elemento común puede o no comprenderse como una misma valoración -por tanto, redundante-. Como se dijo, lo anterior dependerá de la significación delictiva del hecho -esto es, su desvalor-. Si se entiende que la conducta descrita resulta desvalorada exclusivamente en atención a la afectación de un mismo interés, por ejemplo, la indemnidad sexual del menor, uno de los

queda entregado por regla general al caso concreto. Ver también, ETCHEBERRY, cit. (n. 5), pp. 126-127.

${ }^{59}$ Véase MaÑAlich, cit. (n. 2), p. 513. 
tipos penales concurrentes, en este caso el contenido en el art. 366 bis del Código penal, representaría en forma completa el desvalor del hecho, resultando entonces redundante la norma de sanción del tipo contenido en el art. 366 quinquies y, en este sentido, inaplicable externamente por aplicación de la regla de preferencia "consunción". En este caso podemos sostener que opera tal regla en la medida que el tipo desplazado solo representaría una forma menos intensa de protección del mismo interés. En cambio, si del ejercicio interpretativo llevado previamente a cabo, se decide que el hecho también resulta desvalorado por un fundamento diverso al anteriormente descrito -por ejemplo, por afectar otros intereses individuales del afectado-, el resultado de la comparación entre ambos no permitiría sostener que la valoración de tal elemento para la aplicación externa de la norma de sanción del tipo contenido en el art. 366 quinquies, resulta redundante, ya que tal elemento común resultaría valorado en atención a significaciones delictivas diversas y, por lo mismo, no implicaría una infracción a la prohibición de doble valoración. De acá también se extrae que una decisión interpretativa incorrecta desde el punto de vista del contenido de sentido de un tipo penal concurrente, puede traer como consecuencia una decisión igualmente errónea en sede de aplicabilidad de la regla de preferencia de la consunción.

De esta clase de casos se puede extraer una primera manifestación de la regla de preferencia "consunción": R1: Frente a supuestos de interferencia entre tipos penales concurrentes, se aplica la regla de preferencia consunción, si uno de los tipos penales, en su comparación con el otro en lo que respecta a su significación delictiva, puede ser comprendido exclusivamente como una forma de protección menos intensa del mismo interés.

Si se observa bien, una serie de pautas o criterios propuestos por la doctrina para la detección de casos donde operaría el concurso "aparente" por consunción, pueden ser entendidos como manifestaciones de esta regla. Destacan los casos en que se quiere dar cuenta de supuestos que pueden ser subsumidos en tipos de peligro, así como en tipos de lesión, donde operaría la consunción siempre y cuando el tipo de peligro solo pueda ser interpretado como una forma de protección del mismo interés que el tipo de lesión ${ }^{60}$. Así también los supuestos en que con el hecho se afectan intereses de la misma especie de un mismo titular, pero donde

${ }^{60}$ Un supuesto en que sí se aplicaría la regla indicada respecto de tipos de peligro y lesión es el porte de elementos conocidamente destinados para cometer delitos contra la propiedad y estos últimos. Sosteniendo la existencia de consunción, MATUS - Ramírez, cit. (n. 25), p. 510; se desprende lo mismo de Etcheberry, Alfredo, Derecho Penal. Parte especial ( $3^{a}$ edición, Santiago, Editorial Jurídica de Chile, 1999), p. 333, para el cual estamos frente a actos preparatorios de un robo futuro. Es 
uno de los tipos penales concurrentes represente una modalidad de ataque de mayor gravedad, por lo que en la pena asignada a este último se comprenda también formas de afectación menos intensa ${ }^{61}$.

Como resulta evidente, para evitar la aplicación de la regla en cuestión a casos que no caen dentro de su campo de aplicación, resulta fundamental la toma de decisiones interpretativas correctas respecto a la significación delictiva de los tipos concurrentes y la comparación entre los mismos tanto en una dimensión cualitativa -qué intereses protegecomo cuantitativa - esto es, el desvalor asociado a la modalidad de ataque de la que se trate- ${ }^{62}$. Para tales efectos se puede recurrir a una especie de examen de prescindencia de los tipos concurrentes, mediante el cual se pregunta si existe alguna razón normativa -relativa al desvalor del hechoque obligue al tribunal a reconocer la aplicabilidad externa de más de un tipo penal concurrente y, por tanto, prohíba su prescindencia, debido a que parte del desvalor de la conducta no se ve abarcada por el otro tipo concurrente. Por lo mismo, opera como un ejercicio que busca evitar que el tribunal, en contra de lo dispuesto por el ordenamiento jurídicopenal vigente, reconozca un concurso "aparente" ahí donde no existen motivos para sostener que un tipo penal refleje en forma completa o global el desvalor de un hecho. En suma, debido a lo incierta que resulta la aplicación de la regla conviene entonces otorgar criterios para clarificar los supuestos o casos que no pueden caber bajo su campo de aplicación. De esta forma, se podría propender a minimizar su aplicación errónea ${ }^{63}$.

Con todo, y como se podrá apreciar a continuación, frente a supuestos de relación de interferencia entre tipos concurrentes, donde a través de la aplicación del examen recientemente descrito se constate una significación

importante señalar que en este supuesto se estaría más bien frente a un acto anterior copenado.

${ }^{61}$ Relaciones como esta se darían, solo a modo de ejemplo, en el delito de lesiones respecto del homicidio, en este sentido, Politoff - Matus - Ramírez, cit. (n. 6), p. 53; LABATUt, cit. (n. 5), p. 173. Igualmente, en el de abuso sexual respecto de la violación, RodRíGUEZ, cit. (n. 25), pp. 360-361.

${ }^{62}$ Por tal motivo se comprende la relevancia asignada por parte de la doctrina a criterios como la pena asignada al delito para determinar si un tipo penal consume a otro, en la medida que, de acuerdo a ETCHEBERry, cit. (n. 5),p. 124, aquello que caracterizaría a la consunción es que "la ley, al establecer la penalidad de una figura delictiva, ya ha tomado en consideración la gravedad ("desvalor") de otras conductas, también punibles que la acompañan ordinariamente”.

${ }^{63} \mathrm{La}$ aplicación errónea de tal regla implica que la reacción penal frente a un hecho en concreto resulta insuficiente desde el punto de vista de gravedad reconocida por el derecho penal vigente, lo cual podría tener efectos adversos desde el punto de vista del mantenimiento de vigencia de normas. 
delictiva autónoma desde el punto de vista de los intereses protegidos en abstracto por los tipos penales, igualmente podrían esgrimirse argumentos, asociados a la operativización del non bin in idem, para abogar por la aplicación de la regla de preferencia "consunción". Esto quiere decir que la constatación de la significación delictiva autónoma solo en abstracto no permite aún sostener que el caso cae necesariamente bajo el campo de aplicación de la regla derivada del concurso ideal.

b) Aplicación de la regla de preferencia por inherencia.- $\mathrm{Al}$ igual que para el caso anterior, daremos cuenta de un ejemplo que podría resultar problemático desde esta segunda manifestación de la consunción como concreción del non bis in idem: A dispara sobre B, mujer que se encuentra notoriamente embarazada, causando debido al único disparo propinado, la muerte de $\mathrm{B}$ y, por consiguiente, la interrupción del embarazo ${ }^{64}$. A partir del proceso de subsunción respectivo el hecho cae bajo el campo de aplicación tanto del tipo homicidio (inc. $1^{\circ}$, art. 391 del Código penal), como del tipo aborto violento ( $\mathrm{N}^{\circ} 1$, Art. 342 del Código penal ${ }^{65}$ ). Tales tipos penales se encuentran en relación de interferencia, por lo que a partir de tal constatación surge el problema de definir si el caso en particular debe ser resuelto a través de su consideración como un concurso ideal o si, por el contrario, como un concurso aparente por aplicación de la regla de la consunción. Desde el punto de vista de la significación delictiva en abstracto de ambos tipos concurrentes resultaría erróneo sostener que uno de estos no es más que una forma menos intensa de protección del mismo interés que el otro. Así las cosas, en principio el hecho podría ser desvalorado tanto como una afectación a la vida independiente así como por la afectación de un interés diverso, el de la vida dependiente. Esto es, resultaría extraño justificar la aplicación de la regla de preferencia que desplace, por ejemplo, la norma de sanción del aborto, en consideración a que la pena asignada al homicidio contenga el desvalor de la afectación de la vida humana dependiente. Ahora, esto no significa que la regla en comento solo reciba aplicación para tales supuestos, ya que, en definitiva se podría detectar puntos de apoyo normativos para defender la aplicación de la regla de preferencia ya no por razones de significación delictiva común en abstracto, sino más bien debido a que la pena asignada al

${ }^{64}$ Como podremos apreciar, no resulta para nada evidente la solución propuesta para tales casos por MATUS - RAMíreZ, cit. (n. 25), pp. 141-142, según quienes el homicidio consumiría al aborto, en razón de que la penalidad asignada a este último se consideraría insignificante en relación a la mayor establecida para el homicidio.

${ }^{65}$ Obviamente este es solo un ejercicio con fines meramente pedagógicos. Dependiendo del caso podría ser subsumido no solo en el tipo de homicidio, sino que en el supuesto contenido en el art. 343 del Código penal, conocido como "aborto sin propósito de causarlo". 
homicidio contendría el desvalor de aquellos resultados que pueden resultar inherentes -esto es, inevitables- para la consecución del resultado muerte. Sin embargo, y a diferencia del caso anterior donde el vínculo con el non bis in idem resulta bastante más claro, en estos supuestos se podría poner en duda que efectivamente deban ser comprendidos como una manifestación de la prohibición de doble valoración. Si se observa el caso planteado es evidente que desde un punto de vista de la significación delictiva en abstracto de los tipos penales concurrentes -esto es, el objeto de protección de uno y otro- no podemos detectar una relación de redundancia punitiva si es que se optara por la aplicación externa de ambos. Con todo, tal relación también podría presentarse en el caso de que uno de los tipos no presente una significación delictiva autónoma respecto a otro en concreto, en la medida que solo se le otorgue sentido, por ejemplo, como una consecuencia inevitable de la realización de otro de los tipos concurrentes. Con todo, solo podríamos hablar de inherencia en la medida que tal consecuencia inevitable se entienda como accesoria desde el punto de vista del desvalor total del hecho particular. En este sentido, también resultaría correcto sostener que este último consume al primero y que el caso cae bajo el campo de aplicación de la regla de preferencia como una concreción del non bis in idem ${ }^{66}$.

En suma, se puede proponer así una segunda manifestación de la regla de preferencia consunción: R2: Frente a supuestos de interferencia entre tipos penales concurrentes, se aplica la regla de preferencia consunción si uno de los tipos penales, en su comparación con el otro, pierde su significación delictiva autónoma, debido a que resulte inherente a otro tipo concurrente.

La doctrina chilena ha desarrollado especialmente el criterio de la inherencia para aplicar la consunción en casos donde en estricto rigor no puede ser detectada en forma previa una relación de interferencia entre los

${ }^{66}$ Fundamental respecto al vínculo del principio de inherencia con el non bis in idem, Borja, Emiliano, El principio de inherencia del artículo 59 del Código Penal, en Anuario de Derecho Penal y Ciencias Penales 45 (1992), 1, pp. 174 y ss. En Chile, ver Matus, Jean Pierre - Van wezzel, Alex, Artículos 50 al 73, en Politoff, Sergio Ortiz, Luis (dirs.), Texto y comentario del Código Penal chileno (Santiago, Editorial Jurídica de Chile, 2002), I, pp. 350-351, para quienes el art. 63 del Código penal establece la consagración normativa en nuestro medio de la prohibición de doble valoración, entendido como manifestación del non is in ídem, la cual desarrollan como una regla de determinación de pena que prohíbe considerar los elementos que el legislador ya ha tenido en cuenta al momento de tipificar la conducta, además, al mencionado art. le atribuyen el carácter de regla de interpretación general en el Derecho penal chileno, por lo que establecen que su ámbito aplicación va más allá de la relación entre tipos penales y circunstancias modificatorias. También, Couso, cit. (n. 42), pp. 572-578. 
tipos penales concurrentes, sino más bien para supuestos que responden a una lógica diversa, esto es, la del acto copenado, donde la accesoriedad vendría dada tanto por el hecho de que uno de los tipos representa una etapa previa del otro tipo concurrente o una mera consecuencia ${ }^{67} \mathrm{y}$, en este sentido, por la idea de inevitabilidad ${ }^{68}$ o necesidad, así como a supuestos donde uno de los tipos concurrentes resulta insignificante debido a tratarse como meramente acompañante del tipo principal, por ende, la accesoriedad se construiría a través de la idea de "regularidad" 99 . Solo nos interesa acá constatar que la pérdida de significación delictiva autónoma de uno de los tipos concurrentes en relación de interferencia puede estar justificada en razón de que la relación entre ambos, para el caso concreto, sea de inherencia debido a que, en primer lugar, uno de estos solo pueda ser comprendido como una consecuencia inevitable de la realización de otro. En segundo lugar, se debe advertir que la relación de inherencia que interesa para la aplicación de tal regla solo puede extraerse del hecho de que uno de los tipos pierda su significación delictiva autónoma, por lo que del contexto normativo - esto la comparación entre tipos penales- se debe poder concluir que la penalidad asignada a uno de los tipos concurrentes consume el desvalor del otro. Por lo mismo, la mera constatación de que uno resulta una consecuencia inevitable no permitiría aplicar la regla de preferencia, sin consideración a la verificación de que esta conclusión resulta permitida debido a una decisión interpretativa previa: que uno de los tipos comprende en forma completa o global el desvalor del hecho ${ }^{70}$.

${ }^{67}$ Así, por ejemplo, arts. 4 y 8 de ley 20.000, o en general en los delitos de emprendimiento. Parte importante de la doctrina ha desarrollado este criterio bajo la denominación delitos progresivos: MAtus, cit. (n. 6), p. 392; Matus, cit. (n. 1), p. 318; Politoff - Matus - Ramírez, cit. (n. 6), p. 462, Etcheberry, cit. (n. 50), pp. 92-95.

${ }^{68}$ Etcheberry, cit. (n. 50), p. 53, aunque no usa la denominación "inherencia", da cuenta de esta situación de tipos que "acompañan ordinariamente" a otro, por encontrarse en relación de medio a fin; de menos a más; de antecedente necesario $\mathrm{u}$ ordinario a consecuencia necesaria u ordinaria. Similar referencia en ETCHEBERRY, cit. (n. 5), p. 124; NovOA, cit. (n. 5), p. 255 también se refiere a conductas que ordinariamente acompañan al hecho principal.

${ }^{69}$ Matus, Jean Pierre, La teoría del concurso aparente de leyes penales y el "resurgimiento" de la ley en principio desplazada, en Revista de Derecho Universidad Católica del Norte 9 (2002), p. 30-31, postula que el fundamento de este criterio de aplicación de la consunción no es el non bis in idem, sino la insignificancia, entendiendo que en estos casos el reproche del acto principal (que consume al insignificante copenado), sería desproporcionado.

${ }^{70}$ Así, por ejemplo, en el caso del aborto del art. $342 \mathrm{n}^{\circ} 3$, si a consecuencia del aborto resultare la mujer notablemente deforme, ya no sería posible sostener que las lesiones carecen de significancia autónoma, debiendo estas también tener 


\section{BiBLIOGRAFíA}

BASCUR, Gonzalo, Consideraciones acerca de los criterios de unidad de acción en la reciente jurisprudencia penal de la Corte Suprema (2011-2012), en Revista de Derecho Universidad Católica del Norte 23 (2016), 1.

BASCur, Gonzalo, Posesión ilegal de armas de fuego y publicación de la ley n 20.813. ¿Un problema de aplicación temporal de la ley penal más favorable?, en Revista de la Justicia Penal 7 (2017).

BorJA, Emiliano, El principio de inherencia del artículo 59 del Código Penal, en Anuario de Derecho Penal y Ciencias Penales 45 (1992), 1.

Chiassoni, Pierluigi, Técnicas de interpretación jurídica. Breviario para juristas (trad. Pau Luque y Maribel narváez, Madrid, Marcial Pons, 2011).

CiD, José, Notas acerca de las definiciones dogmáticas de concurso de delitos, en Anuario de Derecho Penal y Ciencias Penales 47 (1994).

Couso, Jaime, Comentario al artículo 63, en Couso, Jaime - Hernández, Héctor (dirs.), Código Penal Comentado. Parte General. Doctrina y Jurisprudencia (Santiago, Abeledo Perrot - LegalPublishing, 2011).

Couso, Jaime, Comentario previo a los art. 74 y 75, en Couso, Jaime - Hernández, Héctor (dirs.), Código Penal Comentado. Parte General. Doctrina y Jurisprudencia (Santiago, Abeledo Perrot - LegalPublishing, 2011).

Cuerda Riezú, Antonio, Concurso de delitos y determinación de pena (Madrid, Editorial Tecnos, 1992).

Cury, Enrique, Derecho Penal. Parte General (8a edición, Santiago, Ediciones Universidad Católica de Chile, 2005).

ETCHEBERRY, Alfredo, El concurso aparente de leyes penales (Santiago, Editorial Jurídica de Chile, Colección de seminarios e institutos, volumen II, 1957).

Etcheberry, Alfredo, Derecho Penal. Parte General (3a edición, Santiago, Editorial Jurídica de Chile, 1999), II.

Etcheberry, Alfredo, Derecho Penal. Parte Especial (3a edición, Santiago, Editorial Jurídica de Chile, 1999), III.

FERRER, Jordi - RODRÍGUEZ, Jorge Luis, Jerarquías normativas y dinámica de los sistemas jurídicos (Madrid, Marcial Pons, 2011).

Garrido, Mario, Derecho Penal. Parte Especial (4a edición, Santiago, Editorial Jurídica de Chile, 2010), III.

Garrido, Mario, Derecho Penal. Parte General (4ª edición, Santiago, Editorial Jurídica de Chile, 2007), II.

Gimbernat, Enrique, Concurso de leyes, error y participación en el delito (A propósito del libro del mismo título del profesor Enrique Peñaranda), en Anuario de Derecho Penal y Ciencias Penales 45 (1992), 3.

GuASTINI, Riccardo, Interpretación y construcción jurídica, en Isonomía 43 (2015).

Hernández, Héctor, Actividad administrativa, procedimiento sancionatorio-administrativo y proceso penal: algunas necesidades de coordinación legal, en ARANCIBIA, Jaime - Alarcón, Pablo (coords.), Sanciones Administrativas. X jornadas de Derecho Administrativo, Asociación de Derecho Administrativo (Santiago, Thomson Reuters, 2014).

repercusiones a efectos de la determinación de la pena a través del artículo 75 del Código penal. Sostiene la misma solución MATUS - RAMíreZ, cit. (n. 24), p. 144 
ITURRALDE, Victoria, Interpretación literal y significado convencional. Una reflexión sobre los límites de la interpretación jurídica (Madrid, Marcial Pons, 2014).

KLUG, Ulrich, Sobre el concepto de concurso de leyes (trad. de Jorge M. Seña), en Garzón, Ernesto - Zimmerling, Ruth (revs.), Problemas fundamentales de la filosofia y de la pragmática del derecho (Barcelona-Caracas, Alfa, 1989).

Labatut, Gustavo, Derecho Penal. Parte General (9a edición, actualizada por Julio Zenteno, Santiago, Editorial Jurídica de Chile, 1995), I.

MacCormick, Neil, Retórica y Estado de Derecho. Una teoría del razonamiento jurídico (trad. de José Ángel Gascón, Lima, Palestra editores, 2016).

Mañalich, Juan Pablo, El concurso de delitos. Bases para su reconstrucción en el derecho penal de Puerto Rico, en Revista Jurídica de la Universidad de Puerto Rico 74 (2005).

Mañalich, Juan Pablo, El principio ne bis in idem en el derecho penal chileno, en Revista de Estudios de la Justicia 15 (2011).

Mañalich, Juan Pablo, El principio ne bis in idem frente a la superposición del derecho penal y el derecho administrativo sancionatorio, en Revista Politica Criminal 9 (2014), 18.

MaŃalich, Juan Pablo, El concurso aparente como herramienta de cuantificación penológica de hechos punibles, en CÁRDENAS,, Claudia - FERDMAN, Jorge (coords.), El Derecho Penal como teoría y como práctica. Libro en homenaje a Alfredo Etcheberry Orthusteguy (Santiago, LegalPublishing, 2016).

Maldonado, Francisco, Delito continuado y concurso de delitos, en Revista de Derecho (Valdivia) 28 (2007), 2.

Maldonado, Francisco, Reiteración y concurso de delitos. Consideraciones sobre el artículo 351 del Código Procesal Penal a partir de la teoría general del concurso de delitos en el derecho chileno, en CÁRDENAS, Claudia - FERDMAN, Jorge (coors.), El Derecho Penal como teoría y como práctica. Libro en homenaje a Alfredo Etcheberry Orthusteguy (Santiago, LegalPublishing, 2016).

Marmor, Andrei, Interpretación y teoría del derecho (Barcelona, Gedisa, 2001).

Martínez, David, Metodología jurídica y argumentación (Madrid, Marcial Pons, 2010).

Matus, Jean Pierre, Comentario a los Artículos 74 a 78, en Politoff, Sergio - OrTíz, Luis (dirs.), Matus, Jean Pierre (coord..), Texto y comentario del Código Penal chileno, Tomo I, Libro Primero - Parte General (Santiago, Editorial Jurídica de Chile, 2002).

MATUS, Jean Pierre, La teoría del concurso aparente de leyes penales y el "resurgimiento" de la ley en principio desplazada, en Revista de Derecho Universidad Católica del Norte 9 (2002).

MATus, Jean Pierre, El concurso aparente de leyes penales (Santiago, Ediciones Jurídicas de Santiago, 2008).

Matus, Jean Pierre - Ramírez, María Cecilia, Manual de Derecho Penal Chileno. Parte Especial (Valencia, Tirant lo Blanch, 2017).

Matus, Jean Pierre - Van wezzel, Alex, Artículos 50 al 73, en Politoff, Sergio Ortíz, Luis (dirs.), Texto y comentario del Código Penal chileno, Tomo I, Libro Primero - Parte General (Santiago, Editorial Jurídica de Chile, 2002).

Moreso, José Juan - Vilajosana, Josep María, Introducción a la teoría del derecho (Madrid, Marcial Pons, 2004).

Muñoz, Humberto, Contribución al estudio de la teoría de los concursos de delitos, en Revista Chilena de Derecho Pontificia Universidad Católica de Chile 13 (1986), 2.

Navarro, Pablo - Moreso, José Juan, Aplicabilidad y eficacia de las normas jurídicas, en Isonomía 5 (1996). 
NovoA, Eduardo, Curso de Derecho Penal Chileno. Parte General (3a edición, Santiago Editorial Jurídica de Chile, 2005), II.

Ossandón, Magdalena, El legislador y el principio del ne bis in idem, en Revista Política Criminal 13 (2018), 26.

Peñaranda, Enrique, Concurso de leyes, error y participación en el delito (Madrid, Editorial Civitas, 1991).

Politoff, Sergio - Grisolía, Francisco - Bustos, Juan, Derecho penal chileno. Parte Especial. Delitos contra el individuo en sus condiciones físicas (2a edición, Santiago, Editorial Jurídica de Chile, 2001).

Politoff, Sergio - Matus, Jean Pierre - Ramírez, Cecilia, Lecciones de Derecho penal chileno. Parte general (2a edicion, Santiago, Editorial Jurídica de Chile, 2004).

PRAmBS, Claudio, ¿Es posible sancionar las lesiones y el homicidio en concurso ideal?, en Revista de Derecho de la Pontificia Universidad Católica de Valparaíso 34 (2010).

RAz, Joseph, Entre la autoridad y la interpretación. Sobre la teoría del derecho y la razón práctica (trad. de Hernán Bouvier y Pablo Navarro, Madrid, Marcial Pons, 2013).

Rodríguez, Luis, Delitos sexuales (2a edición, Santiago, Editorial Jurídica de Chile, 2014).

SAINZ, Ángel, El concurso de delitos. Aspectos de política legislativa (Valladolid, Universidad de Valladolid, 1986).

SCHAUER, Frederick, Las reglas en juego. Un examen filosófico de la toma de decisiones basada en reglas en el derecho y en la vida cotidiana (trad. de Claudina Orunesu y Jorge Rodríguez, Madrid, Marcial Pons, 2004). 